\title{
El raloxifeno es equivalente al tamoxifeno para la prevención del cáncer de mama en mujeres posmenopaúsicas de alto riesgo
}

Raloxifen is similar to tamoxifen for breast cancer prevention in high risk postmenopausic women

Vogel VG y col. JAMA. 2006;295:2727-41

Objetivo

Comparar la seguridad y la eficacia del raloxifeno y del tamoxifeno para la prevención del cáncer de mama (CM).

\section{Diseño}

Ensayo clínico controlado aleatorizado y doble ciego.

Lugar

200 centros de Norte América.

\section{Pacientes}

19.747 mujeres pos-menopaúsicas (promedio de 58,5 años) con riesgo aumentado de CM (promedio 4,03\%).

\section{Intervención}

$20 \mathrm{mg} / \mathrm{d}$ ía de tamoxifeno y $60 \mathrm{mg} / \mathrm{día}$ de raloxifeno durante cinco años.

\section{Medición de resultados principales}

Incidencia de CM invasivo, cáncer uterino, CM no invasivo, fracturas óseas y eventos trombo-embólicos.

\section{Resultados principales}

Se observaron 163 casos de CM invasivo en el grupo tamoxifeno y 168 en el grupo raloxifeno. Hubo menos casos de CM no invasivo en el grupo tamoxifeno ( 57 vs. 80 , significancia estadística en el límite). Los eventos trombo-embólicos fueron levemente menos frecuentes en el grupo raloxifeno. Ver tabla 1.
Hubo menor incidencia de cataratas en el grupo raloxifeno (RR 0,79 ; IC95\% 0,68-0,92). No se observaron diferencias en la mortalidad por otros cánceres ni por enfermedad cardiovascular.

Tabla 1: resultados luego de cinco años de tratamiento preventivo con raloxifeno o tamoxifeno en mujeres post-menopáusicas con riesgo aumentado de cáncer de mama.

\begin{tabular}{|c|c|c|c|c|}
\hline & \multicolumn{2}{|c|}{$\begin{array}{l}\text { Wúmero de pacientes por grupo e } \\
\text { incidencia (casos/1000) }\end{array}$} & \multirow[b]{2}{*}{$\begin{array}{l}\text { Riesgo relativo } \\
\text { (1695\%) }\end{array}$} \\
\hline & & $\begin{array}{l}\text { Raloxifeno } \\
\text { (n=9745) }\end{array}$ & $\begin{array}{c}\text { Tamoxifeno } \\
(n=9726)\end{array}$ & \\
\hline \multirow{2}{*}{$\begin{array}{l}\text { Cáncer } \\
\text { de mama }\end{array}$} & Invasivo & $168(4,41)$ & $163(4,3)$ & $1,02(0,82-1,28)$ \\
\hline & No invasivo & $80(2,11)$ & $57(1,51)$ & $1,40(0,98-2,0)$ \\
\hline \multicolumn{2}{|c|}{ Cáncer de útero } & $23(1,25)$ & $36(2)$ & $0,62(0,35-1,08)$ \\
\hline \multicolumn{2}{|c|}{ Tromboembólismo } & $100(2,61)$ & $141(3,71)$ & $0,70(0,54-0,91)$ \\
\hline \multicolumn{2}{|c|}{ Mortalidad } & $101(2,49)$ & $96(2,64)$ & $0,94(0,71-1,26)$ \\
\hline
\end{tabular}

\section{Conclusiones}

El raloxifeno y el tamoxifeno son equivalentes en cuanto a sus efectos para reducir la incidencia de cáncer de mama en mujeres posmenopáusicas con mayor riesgo de desarrollarlo. El raloxifeno se asocia a menor riesgo de eventos tromboembólicos y cataratas y a un leve pero no significativo aumento del riesgo de CM no invasivo.

Palabras claves: cáncer de mama, tamoxifeno, raloxifeno, prevención. Key words: breast cancer, tamoxifen, raloxifen.

Fuente de financiamiento: Eli Lilly \& AstraZeneca Pharmaceuticals

\section{Comentario}

El tamoxifeno y el raloxifeno son moduladores selectivos del receptor estrogénico. En 1998 la Aministración de Drogas y Alimentos de EEUU (FDA) aprobó el uso de tamoxifeno para la prevención del $\mathrm{CM}$ en mujeres con mayor riesgo. Sin embargo, el tamoxifeno puede aumentar el riesgo de cáncer de endometrio, de tromboembolia y de cataratas. Otro efecto adverso que se ha visto frecuentemente es el aumento los síntomas menopáusicos (fundamentalmente sofocos y sequedad vaginal). La hipótesis sobre el beneficio del raloxifeno surgió a partir de su estudio para su uso en osteoporosis en mujeres posmenopáusicas, en quienes mostró una incidencia menor de CM invasor'.

Los resultados del presente estudio muestran que ambas drogas fueron equivalentes para reducir la incidencia del CM invasor en mujeres con mayor riesgo, respecto de la incidencia esperada de acuerdo a datos históricos, con el valor agregado de que el raloxifeno logró similar eficacia con una menor incidencia de efectos secundarios que el tamoxifeno. Los resultados, alentadores para el raloxifeno, mostraron una reducción no significativa de la incidencia de cánceres uterinos; menos casos de embolismos pulmonares y trombosis de vena profunda, así como reducción de cataratas.

\section{Conclusiones del comentador}

Quedan pendientes aun algunos interrogantes a responder antes de pensar en reemplazar al tamoxifeno, ya que este ha sido aprobado tanto para mujeres premenopáusicas como posmenopáusicas y además, el raloxifeno no resultó tan eficaz como el tamoxifeno para controlar la incidencia del CM no invasivo (Iobular in-situ y ductal in-situ) lo que coincide con investigaciones anteriores $^{2}$

Discaciati V. El raloxifeno fue similar al tamoxifeno en la reducción de cáncer de mama en mujeres pos-menopaúsicas con riesgo aumentado. Evid. actual. práct. ambul; 10(1):6, ene-feb.2007 Comentado de: Vogel VG, Costantino JP, Wickerham DL et al (STAR). Effects of tamoxifen vs raloxifene on the risk of developing invasive breast cancer and other disease outcomes: the NSABP Study of Tamoxifen and Raloxifene (STAR) P-2 trial. JAMA. 2006 Jun 21;295(23):2727-41. PMID: 16754727. Disponible en URL: http://jama.ama-assn.org/cgi/reprint/295/23/2727

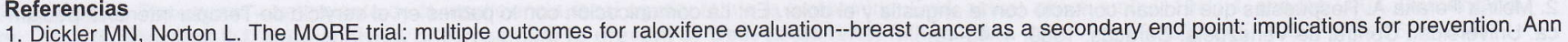
N Y Acad Sci. 2001 Dec; 949:134-42.

2. Carnes K. El raloxifeno es eficaz para prevenir el cáncer de mama: el medicamento usado en el tratamiento de la osteoporosis supera a tamoxifeno en el ensayo clínico nacional STAR. OncoLog. mayo 2006, Vol. 51, No. 5. 